\title{
APLIKASI DESKTOP PASIEN RAWAT JALAN PADA KLINIK MEKAR SARI MEDIKA MENGGUNAKAN METODOLOGI BERORIENTASI OBYEK
}

\author{
Padeli $^{1}$ \\ Syarah $^{2}$ \\ Rahmat Hidayat ${ }^{3}$ \\ Email :padeli@raharja.info, syarah@raharja.info, rahmat.hidayat@ raharja.info
}

\begin{abstract}
Pursue the world of business in the health sector needs support right information to manage health care services for the purpose of a health service can be implemented as expected. The dependence in the business world of computer-based information systems is rapidly increasing, making it difficult for a business organization to compete without the support of information systems that address the needs mempu. In this matter as a desktop application into an ease of software in any application of computerized technology, as well as software (software). A desktop application that is designed to be answering the needs of users, who apply into the computerized system. So from that point on in the wake of an application can improve the system must be ensured before. Thus, as stated above, the Blooms Sari Medical Clinic is an organization that is engaged in work to improve health care quality and patient information needed in order to be accepted quickly and precisely so that the quality of service standards can be satisfied. To achieve these objectives, Sari Medical Clinic blooms are still using manual system of recording data in particular, causing health care to the patient to be slow. To answer this, we need a system of outpatient health services to support the smooth. The key to successful implementation of an outpatient information system is to understand the needs of the administration of the Medical Clinic and Sari Bloom understands the development of strategies that can facilitate the adoption and use of a new technology.
\end{abstract}

Keywords: Medical Clinic Sari Bloom, Desktop Applications

\begin{abstract}
ABSTRAKSI
Menekuni dunia bisnis dalam bidang kesehatan memerlukan dukungan informasi yang tepat dalam mengelola jasa pelayanan kesehatan agar tujuan suatu pelayanan jasa kesehatan dapat terlaksana sesuai harapan. Adanya ketergantungan dalam dunia bisnis terhadap sistem informasi berbasis komputer semakin pesat, sehingga sulit bagi suatu organisasi bisnis untuk berkompetisi tanpa dukungan sistem informasi yang mempu menjawab kebutuhan. Dalam hai ini Aplikasi desktop sebagai perangkat lunak menjadi suatu kemudahaan dalam setiap penerapan teknologi secara komputerisasi, selain sebagai perangkat lunak (software). Suatu aplikasi desktop yang dirancang haruslah menjawab kebutuhan pengguna, yang menerapkan sistem kedalam komputerisasi. Maka dari pada itu aplikasi yang di bangun harus dipastikan bisa memperbaiki sistem sebelumnya. Dengan demikian, sebagaimana telah dikemukakan diatas maka Klinik Mekar Sari Medika yaitu suatu organisasi yang bergerak dalam bidang kesehatan berupaya meningkatkan kualitas pelayanan serta informasi yang dibutuhkan pasiennya agar dapat diterima dengan cepat dan tepat sehingga mutu standar pelayanan dapat memuaskan. Untuk mencapai tujuan tersebut, Klinik Mekar Sari Medika masih menggunakan sistem manual khususnya pencatatan data sehingga menyebabkan pelayanan kesehatan terhadap pasien menjadi lambat. Untuk menjawab hal tersebut, maka diperlukan suatu sistem rawat jalan yang dapat menunjang kelancaran pelayanan kesehatan. Kunci sukses implementasi suatu sistem informasi rawat jalan adalah memahami kebutuhan administrasi pada Klinik Mekar Sari Medika dan mengerti strategi pengembangan sehingga mampu menjembatani adopsi dan pemanfaatan suatu teknologi baru.
\end{abstract}

Kata Kunci : Klinik Mekar Sari Medika, Aplikasi Desktop 


\section{PENDAHULUAN}

Aplikasi desktop sebagai perangkat lunak menjadi suatu kemudahaan dalam setiap penerapan teknologi secara komputerisasi, selain sebagai perangkat lunak (software). Suatu aplikasi desktop yang dirancang haruslah menjawab kebutuhan pengguna, yang menerapkan sistem kedalam komputerisasi. Maka dari pada itu aplikasi yang di bangun harus dipastikan bisa memperbaiki sistem sebelumnya.

Pada klinik Mekar Sari Medika pengolahan data pasien rawat jalan dilakukan secara sederhana, sehingga sering terjadi keterlambatan dalam proses penyusunan laporan serta hasil yang di dapat terkadang kurang meyakinkan. Pemanfaatan Aplikasi desktop ini dilakukan dalam menyelesaikan kegiatan pengelolaan data, merupakan suatu langkah tepat dalam mencapai hasil yang optimal. Sehingga akan menemui sistem yang terkomputerisasi dan terintegrasi dalam mempermudah record suatu laporan.

Latar belakang ini bedasarkan permasalahan yang dihadapi oleh klinik mekar sari medika. Sistem yang manual tidak lagi efektif dan juga data pasien yang hampir bertambah setiap harinya menjadi suatu permasalahan jika kesulitan dalam pencarian data pasien. Sehingga diperlukan sistem pengelola data yang menggunakan komputer sebagai alat bantu dan aplikasi desktop sebagai software yang mempermudah dalam

prosesnya. Serta dapat menyajikan informasiinformasi untuk membantu kinerja Klinik Mekar Sari Medika.

Dari permasalahan yang telah penulis ungkapkan diatas, maka penulis dapat menyimpulkan dengan judul "Aplikasi Desktop Pendataan Pasien Rawat Jalan Pada Klinik Mekar Sari Medika Menggunakan Visual Basic 9.0."

\section{METODELOGI PENELITIAN}

Metode pengerjaan proyek ini juga menggunakan metode SDLC (Software Development Life Cycle) dengan model prototype dengan tahap-tahap sebagai berikut:

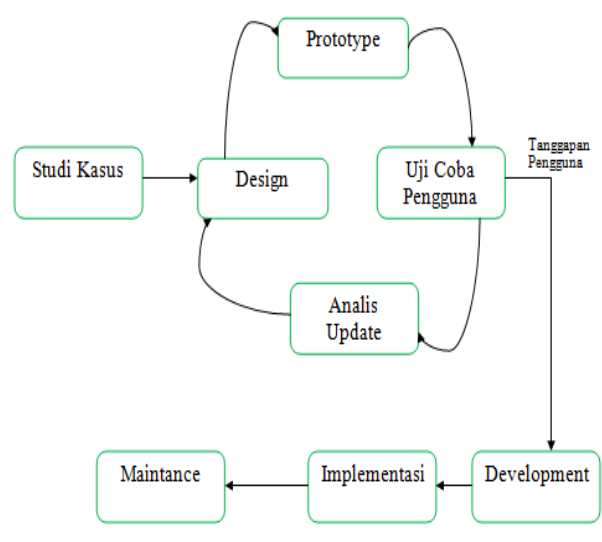

Gambar 1. Prototype Model

1. Visual Basic. Net (VB.9.0)

Microsoft Visual Basic .NET adalah generasi selanjutnya dari visual basic, yang memungkinkan untuk membangun sebuah aplikasi database client atau server yang bergerak di atas sistem .NET Framework, dengan menggunakan bahasa BASIC. Dengan menggunakan alat ini, para programmer dapat membangun aplikasi dengan mengklasifikasikan sesuai dengan pengguna antara lain: (Junindar, 2008: 03)

a. Windows Aplication Adalah aplikasi yang paling umum dibuat, menggunakan antarmuka windows. Biasanya, windows application merupakan interface aplikasi, sedangkan logic aplikasi terdapat didalam Class Library.

b. Class Library Merupakan fondasi dasar untuk membuat komponen yang menjalankan funsi tertentu. Dalam pemograman yang berorientasi objek class merupakan fondasi dasar untuk membentuk objek.

c. Windows Control Library Merupakan kelebihan dari Visual basic dimana pengguna dapat menentukan kontrolnya sesuai dengan kebutuhan yang menginstruksikan beberapa fungsi yang di perintahkan untuk control tersebut. 


\section{Unified Modeling Language (UML)}

Menurut Chonoles "UML singkatan dari Unified Modeling Language yang berarti bahasa pemodelan standar." UML memiliki sintaks dan semantik. Ketika membuat model menggunakan konsep $U M L$ ada aturan-aturan yang harus diikuti. Bagaimana elemen pada model-model yang kita buat berhubungan satu dengan lainya harus mengikuti standar yang ada. $U M L$ telah diaplikasikan dalam bidang investasi perbankan, lembaga kesehatan, departemen pertahanan, sistem terdistribusi, sistem pendukung alat kerja, retail, sales, supplier ataupun lainya. (Widodo dan Herlawati, 2011: 06)

\section{a. Diagram-Diagram UML}

Widodo dan Herlawati (2011: 10) Dalam bukunya menyebutkan, bahwa $U M L$ menyediakan 9(Sembilan) jenis diagram, yang lain menyebutkan 8(delapan), karena ada beberapa diagram yang di gabung, misalnya diagram komunikasi, diagram urutan dan diagram perwaktuan menjadi diagram interaksi. Namun demikian modelmodel itu dapat dikelompokan bedasarkan sifatnya yaitu jenis statis atau dinamis Jenis diagram itu antara lain:

- Use Case Diagram

- Activity Diagram

- State Machine Diagram

- Sequence Diagram

- Class Diagram

- Package Diagram

\section{Pemrograman Berorientasi Objek}

Program adalah suatu bentuk aplikasi atau bisa juga disebut software yang dibuat dengan menggunakan. Bahasa Pemrograman dan dapat menyelesaikan suatu tugas, fungsi, perhitungan dengan menggunakan komputer. Bahasa pemrograman merupakan kumpulan perintah-perintah yang dimengerti komputer untuk melakukan tugas-tugas tertentu. Sedangkan pemrograman atau programming merupakan teknik untuk membuat suatu program dengan menggunakan bahasa pemrograman. Pemrograman Berorientasi Objek (Object Oriented Programming) merupakan teknik membuat suatu program berdasarkan objek. Untuk lebih memudahkan pemahaman tentang objek, saya beri sebuah contoh : Meja, Kursi, Jam Dinding dan yang lainnya merupakan contoh objek. Objek yang disebutkan tadi umumnya berada didalam sebuah ruangan, ruangan apabila kita melihatnya dari sebuah rumah bias juga dikategorikan sebuah objek dan rumah jika dilihat dari cara pandang yang lebih luas lagi juga merupakan objek. Jadi sebuah Objek merupakan suatu bentuk atau model yang tergantung dari cara pandang objek dimaksud.

\begin{tabular}{|c|c|}
\hline No. Shatrate & Hiadrale \\
\hline 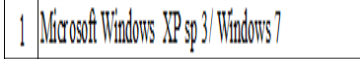 & 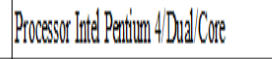 \\
\hline 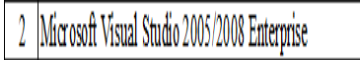 & 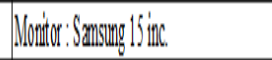 \\
\hline 3 Wiroosat Acess 20032007 & Nonse: Ofitiol \\
\hline 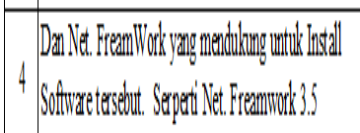 & 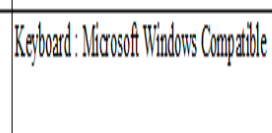 \\
\hline 5 & 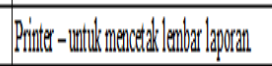 \\
\hline
\end{tabular}

Tabel 1. Daftar software dan Hardware

\section{PERMASALAHAN}

Bedasarkan latar belakang penelitian yang sudah dikemukakan sebelumnya maka penulis dapat menyimpulkan perumusan masalah yang akan didefinisikan dalam penelitian ini, antara lain sebagai berikut :

1. Bagaimanakah proses pendataan pasien rawat jalan yang sedang berjalan saat ini ?

2. Apakah laporan yang dihasilkan dari sistem yang berjalan saat ini datanya sudah akurat?

3. Bagaimana membangun suatu aplikasi desktop yang dapat memudahkan kegiatan pendataan pasien rawat jalan yang efektif dan efisien pada klinik mekar sari medika?

\section{PEMBAHASAN}

1. Analisis Kebutuhan Sistem

Pada perinsipnya Microsoft Visual Basic. 2008 ini membutuhkan prangkat yang memang mendukung agar aplikasi mudah di jalankan dengan dengan visual grafis yang baik, agar terciptanya suatu pencapaian yang 
benar-benar meningkatka mutu dan qualitas serta memberikan efek yang positif terhadap klinik. Sebagai bahan kebutuhan prangkat aplikasi adapun uraiannya sebagai berikut:

Tabel 1. Kebutuhan Software dan Hardware

a. Hak Akses (Brainware)

- Pemilik/ Pimpinan Perusahaan

- Karyawan yang diberi tugas dan Wewenang.

2. Perancangan Sistem

Sistem yang berjalan sebelumnya, menjelaskan bahwa Klinik Mekar Sari Medika menerapkan sistem manual dalam prosesnya. Baik dalam Input Data Pasien, Laporan, atau pun layanan pasien lainya. Manualisasi dalam klinik akan di gantikan dengan pengembangan sistem berbasis komputerisasi. Meskipun ruang lingkup terbatas dalam penerapanya, namun dengan pemanfaatan teknologi Perangkat Lunak(Software) ini diharapkan akan mempermudah kinerja klinik yang lebih menitik beratkan dengan berbasis aplikasi desktop.

Pada usulan prosedur yang baru terdapat tahapan yang nantinya akan diuraikan, diantaranya mengenai perubahan sistem yang digambarkan dalam diagram $U M L$, Basis Data, Rancangan Aplikasi dan lain sebagainya. Visual Basic 9.0 sebagai program yang digunakan untuk pengembangan sistem yang diusulkan. Ini bertujuan agar memudahkan dalam tahapan proses sesuai yang diharapkan. Adapun kelebihan dari sistem yang akan diusulkan, diantaranya :

a. Mencapai peningkatan pengolahan data pasien.

b. Melalui komputerisasi memungkinkan hasil pencarian data secara cepat (efisiensi waktu).

c. Sistem yang dirancang akan mempermudah pengguna dalam penyusunan laporan dari hasil kinerja.
Gambar 2. Proses Pendaftaran Berobat

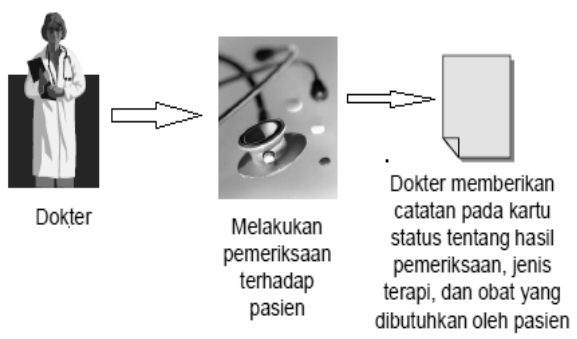

Gambar 3. Proses Pemeriksaan Pasien

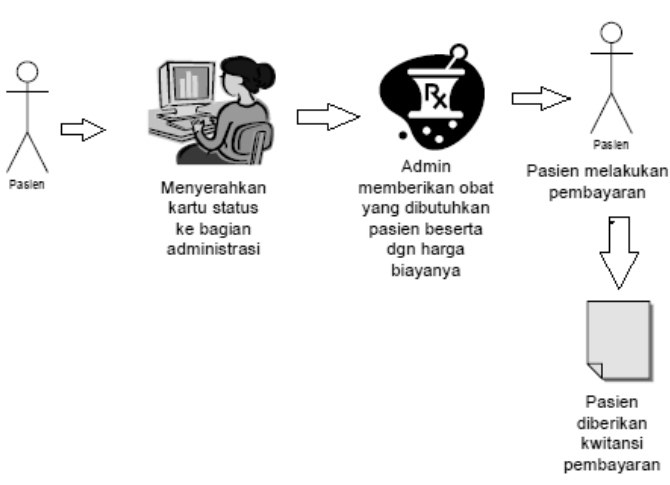

Gambar 4. Input Resep Obat

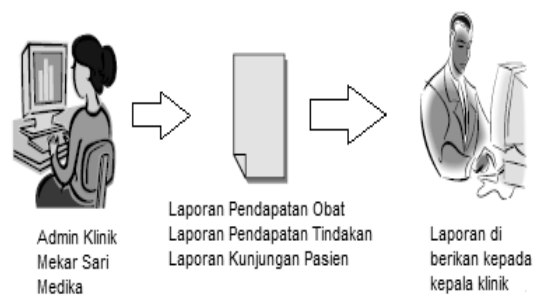

Gambar 5. Proses Laporan Pasien Rawat Jalan

PEMECAHAN MASALAH

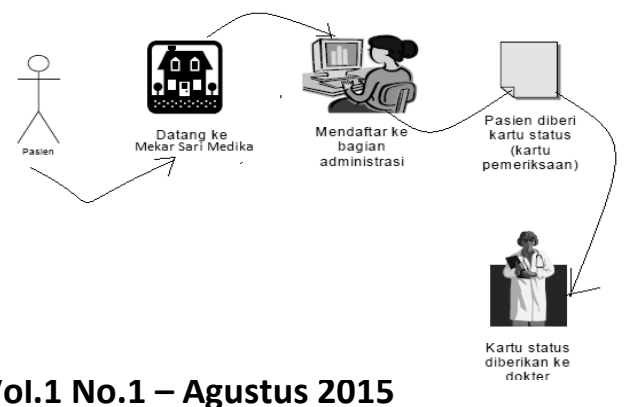

Vol.1 No.1 - Agustus 2015 


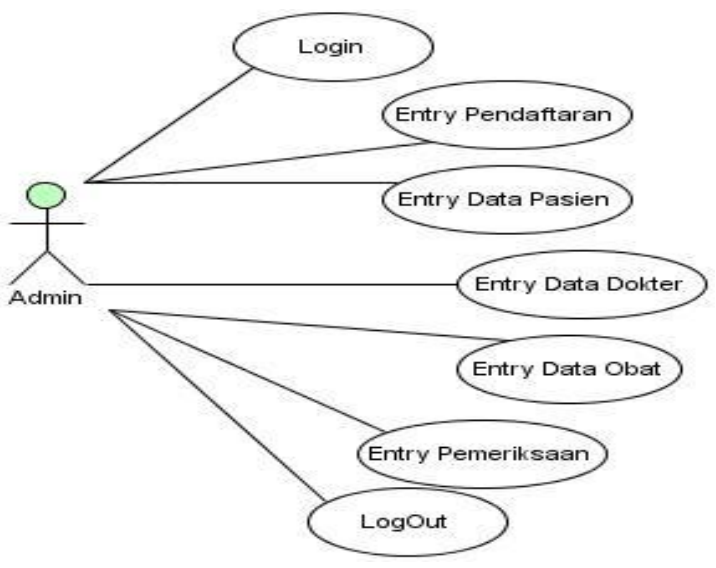

Gambar 6. Use case diagram

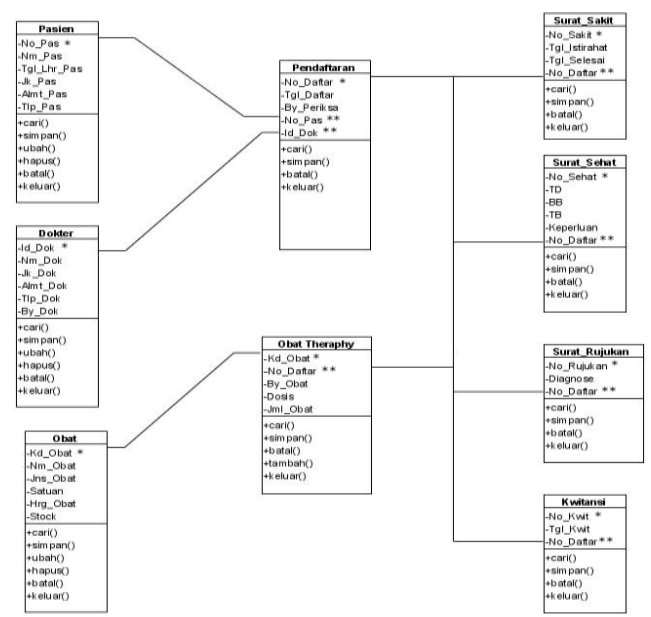

Gambar 7. Class Diagram

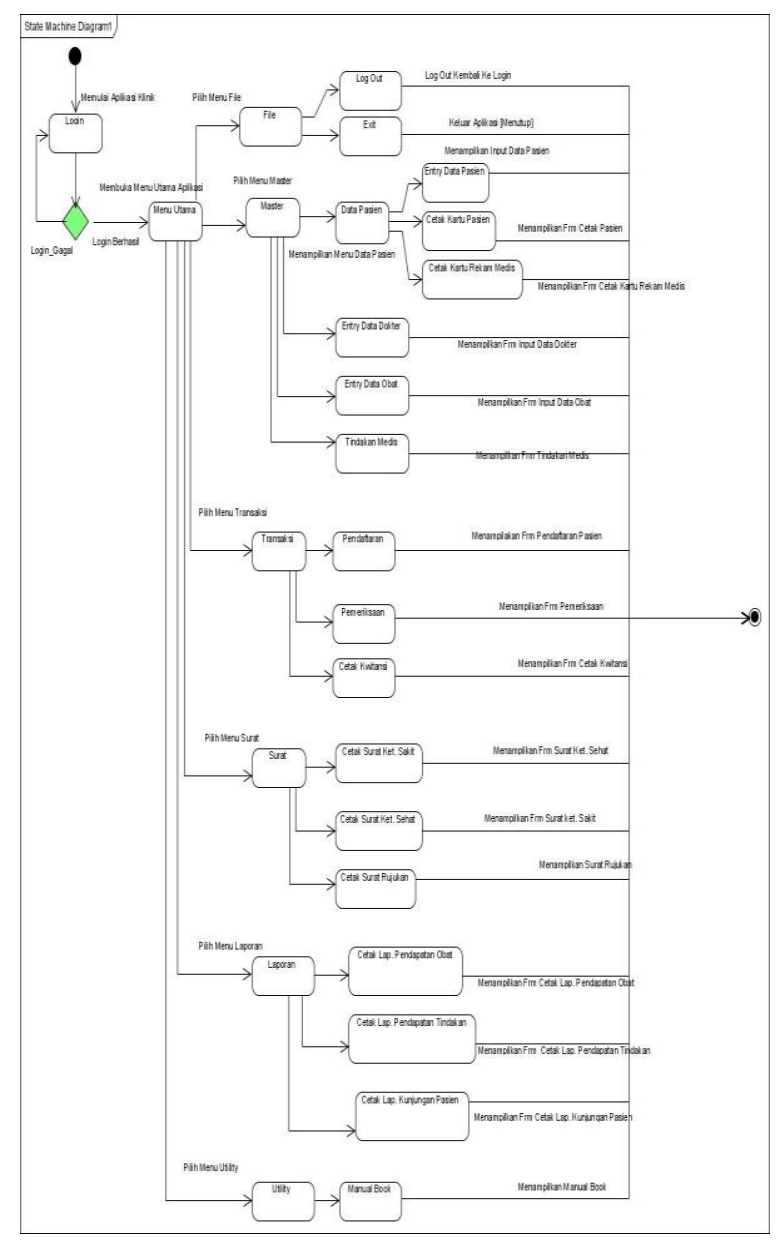

Gambar 8. State Machine Diagram

\section{IMPLEMENTASI APLIKASI}

1. Menu Login

Gambar 9. Menu Login

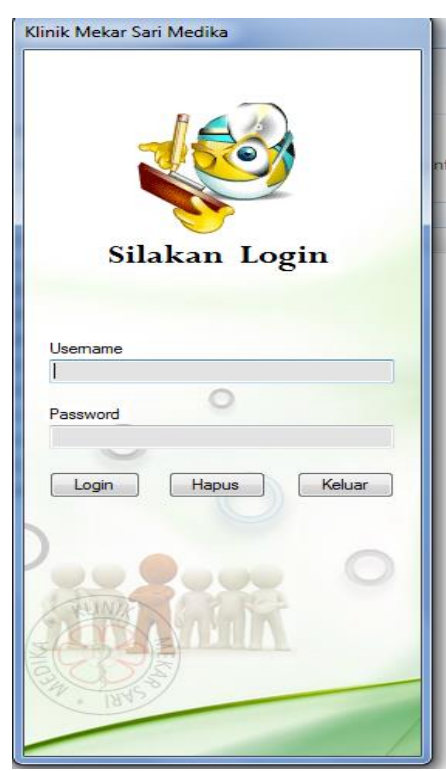

2. Menu Utama

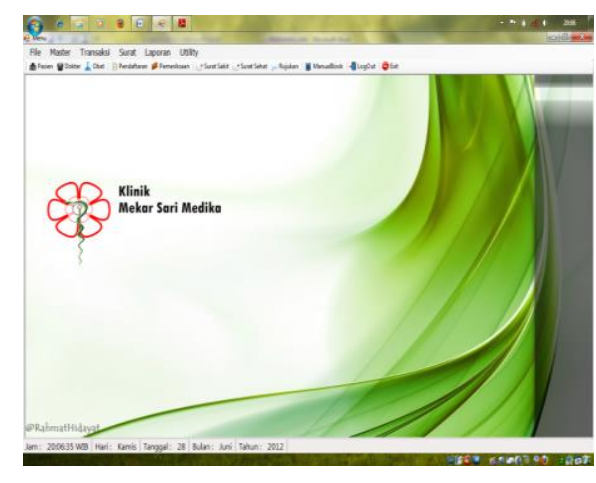

Gambar 10. Menu Utama 


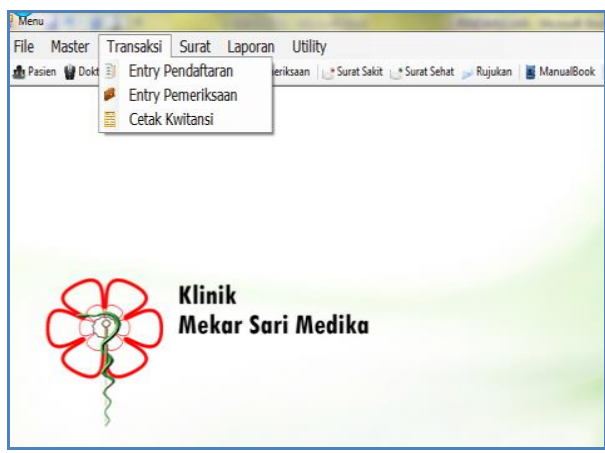

Gambar 11. Menu Master

4. Transaksi

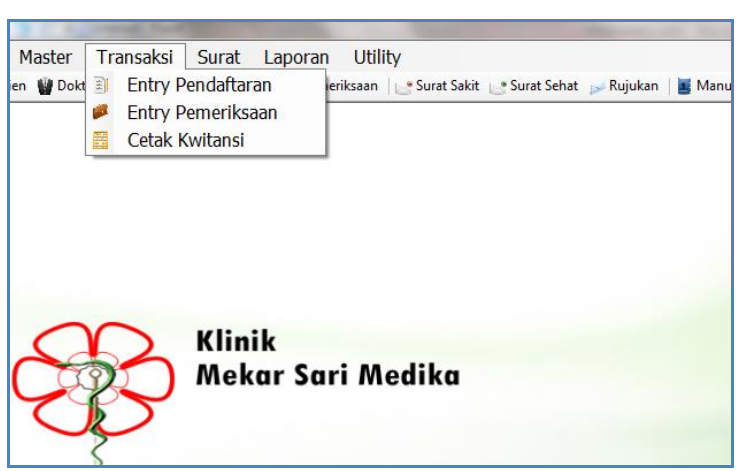

Gambar 12. Menu Transaksi

5. Surat

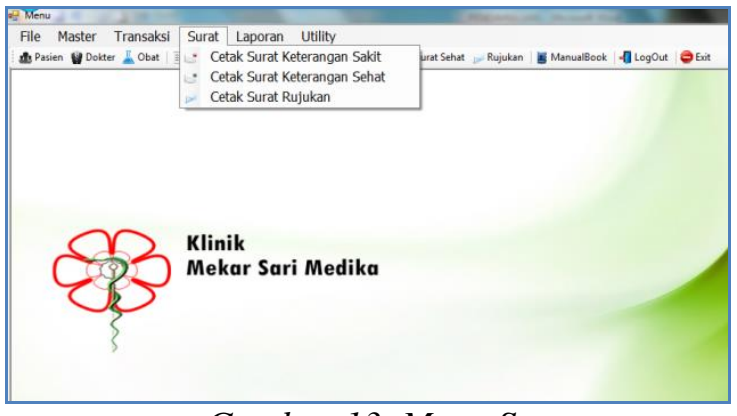

Gambar 13. Menu Surat

6. From Entry Data Pasien

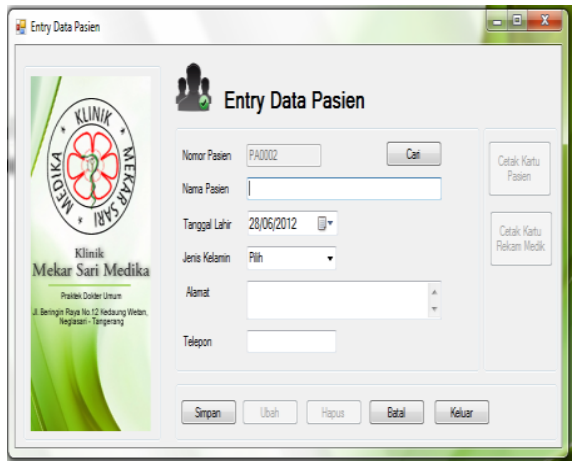

Gambar 14. Form Entry Data Pasien
7. Form Entry Data Dokter

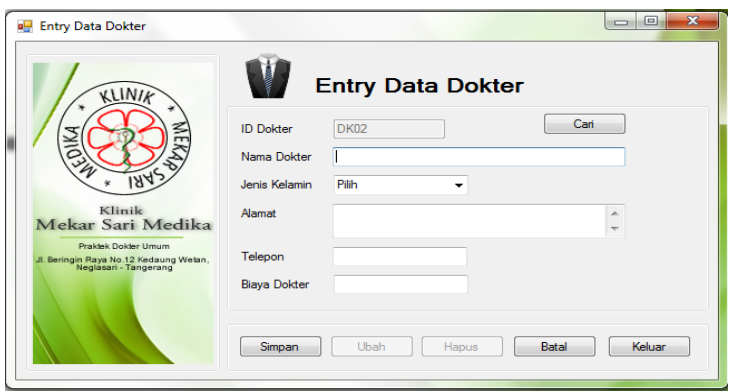

Gambar 15. Entry Data Dokter

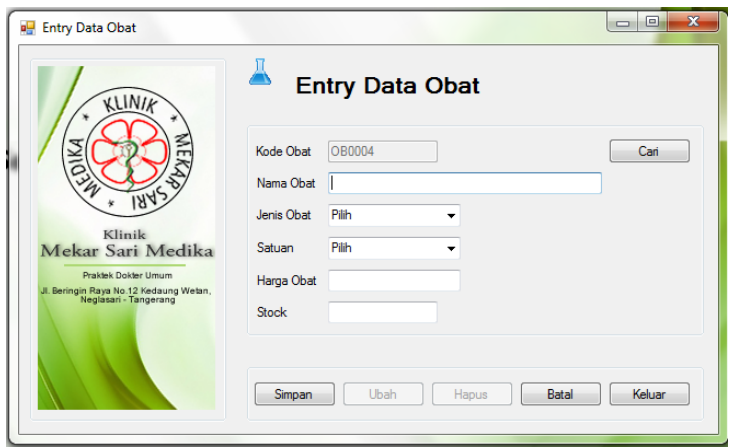

Gambar 16. Form Entry Data Obat

8. Form Entry Pendaftaran

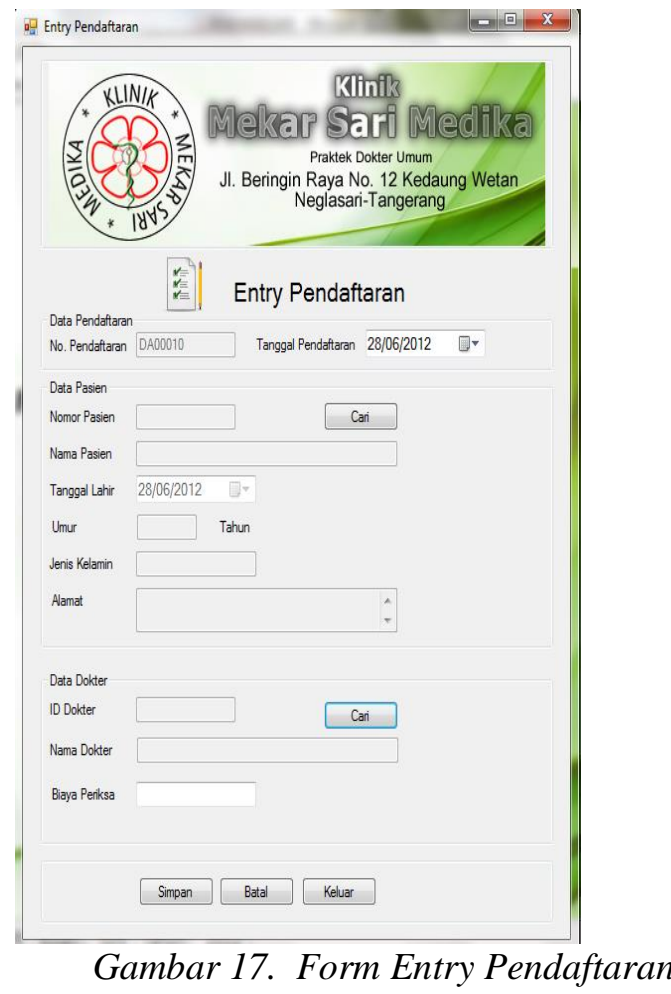

9. Form Entry Pemeriksaan 


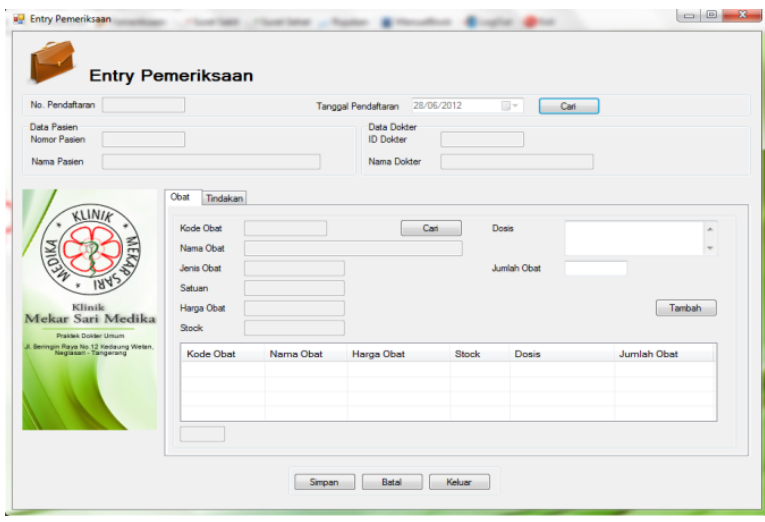

Gambar 18. Form Entry Pemeriksaan

\section{Form Cetak Kwitansi}

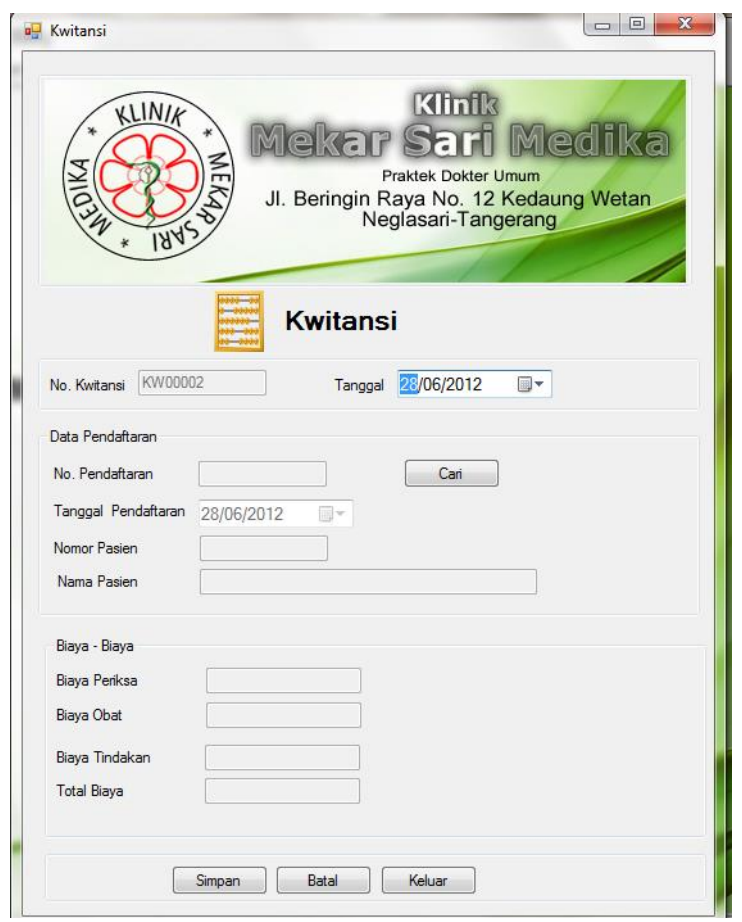

Gambar 19. Form Entry Pemeriksaan

\section{Form Cetak Surat Keterangan Sehat/Sakit}

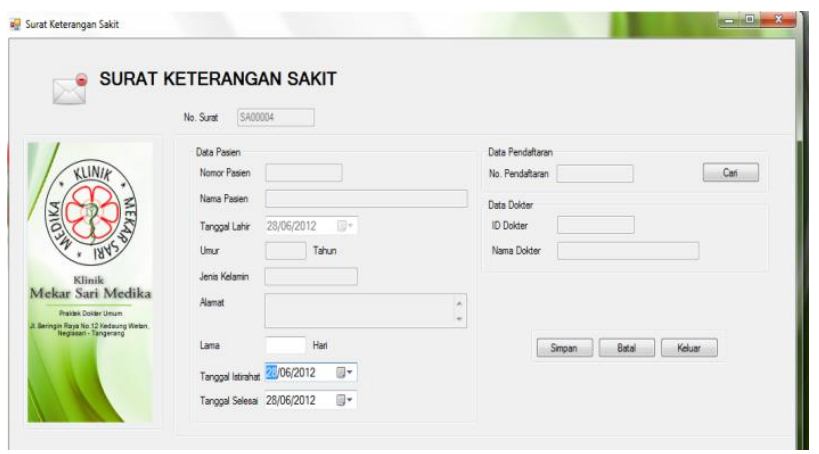

Gambar 20. Form Surat Ket Sakit.

12. Cetak Laporan

Vol.1 No.1 - Agustus 2015

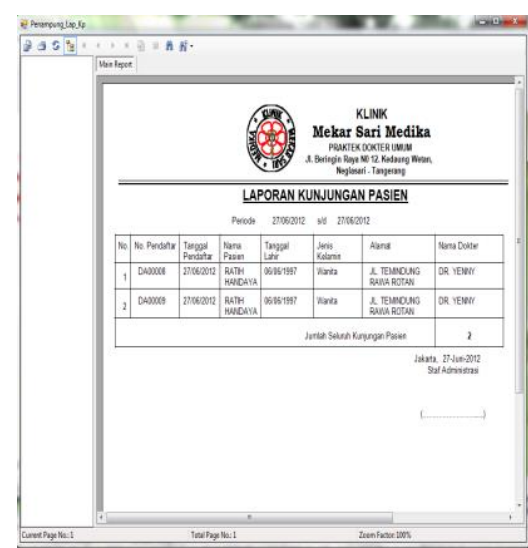

F Gambar 21. Contoh Crystal Report

Dapat disimpulkan bedasarkan hasil penelitian dan pengamatan yang telah dilakukan penulis dengan Aplikasi Desktop pada Klinik Mekar Sari Medika, Dengan ini dapat diperoleh kesimpulan diantranya sebagai berikut:

1. Menggunakan sistem yang masih manual dalam pelaksanaan kinerja klinik, memungkinkan terjadinya kesalahan dalam Input data pasien yang akan berobat, hal tersebut di karenakan terlalu banyaknya jumlah data yang tersusun dalam rak-rak dokumen klinik. Sehingga dalam prosesnya membutuhkan waktu untuk pencarian data tersebut. Maka dari itu diperlukan adanya sistem yang nantinya akan mempermudah dalam prosesnya.

2. Juga pada sistem yang berjalan belum menunjang dalam menyediakan informasi yang dibutuhkan dengan cepat dan akurat. Informasi tersebut berisikan informasi biaya berobat, laporan pelayanan kesehatan dan lain sebagainya.

3. Aplikasi Desktop yang dibangun adalah dengan menggunakan Visual Basic Versi 9.0 (Microsoft), dengan berisikan submenu yang dirancang sesuai dengan kebutuhan klinik dalam memperoleh suatu hasil yang memuaskan.

Dalam kaitanya dengan hal tersebut, Pemanfaatan komputer sebagai alat bantu pengelolahan data yang cepat dan terjamin, maka semua kegiatan yang terjadi dapat mengurangi atau bahkan meminimalkan kesalahan. Serta setiap penggunaan aplikasi yang dilakukan oleh petugas dilakukan dengan penuh 
tanggung jawab, demi terciptanya kualitas dan mutu.

\section{SARAN}

Sebagai suatu bentuk kesempurnaan yang terdapat dalam penelitian dan laporan skripsi ini. Penulis mengajukan beberapa saran kepada pihak yang bersangkutan, agar dalam prospeknya akan menghasilkan harapan baik.

Beberapa saran yang dapat dikemukakan adalah :

1. Meningkatkan Quality Sumber Daya Manusia, yang di harapkan mampu menyusuaikan dengan teknologi yang digunakan.

2. Menciptakan mutu dan tanggung jawab ( Responsibility) dalam perusahaan dengan mewujudkanya pada etos dalam bekerja.

3. Setelah sistem dapat diterapkan dan di implementasikan dengan baik maka tidak menutup kemungkinan untuk dilakukan suatu pengembangan yang baru, agar kekurangan yang ada pada sistem dapat diperbaiki.

4. Menjunjung tingi pemeliharan dan pengontrolan suatu sistem dengan baik. Dan memulai segala sesuatu dengan pemeliharaan dan prosedur yang baik untuk citra baik klinik, sesuai dengan yang diharapkan.

Demikian, saran yang penulis bisa kemukakan agar sekiranya pihak yang bersangkutan bisa mewujdkan beberapa point, untuk kemajuan klinik mekar sari medika.

\section{DAFTAR PUSTAKA}

\section{[Jogiyanto]}

Jogiyanto, (2009). Sistem Teknologi Informasi. Ed. III. Andi Offset, Jogyakarta.

\section{[Widodo dan Herlawati]}

Widodo Pudjo Prabowo, Herlawati, (2011). Menggunakan UML. Informatika, Bandung

\section{[Junindar]}

Junindar, (2008). Panduan Lengkap Menjadi Programmer. Media Kita, Jakarta Selatan.

\section{[Sadeli]}

Sadeli Muhammad. (2009). Visual Basic 2008 untuk Orang Awam. Maxikom, Palembang. 